\title{
mRNA Transcript Analysis of Hypothesis-driven Pathways as Known Responders to Organophosphate Exposure: Rhinella Arenarum Larvae Transcriptome Study
}

\section{Natalia Pires}

Centro de Investigaciones en Toxicología Ambiental y Agrobiotecnología del Comahue (CITAAC), Universidad Nacional del Comahue-CONICET

\section{Cecilia Lascano}

Centro de Investigaciones en Toxicología Ambiental y Agrobiotecnología del Comahue (CITAAC), Universidad Nacional del Comahue-CONICET

\section{Danilo Ceschin}

Unidad de Bioinformática Traslacional, Centro de Investigación en Medicina Traslacional Severo Amuchástegui, Instituto Universitario de Ciencias Biomédicas de Córdoba

\section{Andrés Venturino ( $\square$ aventu1@yahoo.com.ar)}

Centro de Investigaciones en Toxicología Ambiental y Agrobiotecnología del Comahue (CITAAC), Universidad Nacional del Comahue-CONICET

\section{Research Article}

Keywords: Transcriptomics, amphibian, organophosphorus pesticides, molecular targets, signaling pathways, housekeeping genes

Posted Date: January 5th, 2022

DOI: https://doi.org/10.21203/rs.3.rs-1189243/v1

License: (1) This work is licensed under a Creative Commons Attribution 4.0 International License. Read Full License 


\section{Abstract}

Transcriptional analysis of the network of transcription regulators and target pathways in exposed organisms may be a hard task when their genome remains unknown. We used a whole transcriptome study on Rhinella arenarum larvae exposed to the organophosphorus pesticides azinphos-methyl and chlorpyrifos to evaluate transcriptional effects on a priori selected groups of genes. This approach allowed us to evaluate the effects on hypothesis-selected pathways such as target esterases, detoxifying enzymes, polyamine metabolism and signaling and regulatory pathways modulating them. We could then compare the responses at the transcriptional level with previously described effects at the enzymatic or metabolic levels to obtain global insight into toxicity-response mechanisms. The effects of both pesticides on the transcript levels of these pathways could be considered moderate, while the responses elicited by chlorpyrifos were more potent and earlier than those elicited by azinphos-methyl. Finally, we infer a prevailing downregulation effect of pesticides on signaling pathways and transcription factor transcripts encoding products that modulate/control the polyamine and antioxidant response pathways. We additionally tested and selected potential housekeeping genes based on those reported for other species. These results allow us to go through future confirmatory studies on pesticide gene expression modulation in toad larvae.

\section{Introduction}

The amphibian Rhinella arenarum (Hensel 1867) is widely distributed throughout Argentina and partially in South America ${ }^{1}$. Its life cycle includes two fundamental stages before reaching the adult stage: the embryonic and larval stages. The physiological reproduction of the species in the Upper Valley of Rio Negro and Neuquén (North Patagonia) occurs once a year during the spring months in backwaters and irrigation channels. The reproductive season coincides with the period of greatest pesticide application to protect fruit production (INTA, 1993). Various kinds of pesticides have been detected in superficial waters where amphibian reproduction occurs ${ }^{2}$. This situation implies that both $R$. arenarum embryos and larvae are potentially exposed, at least temporarily, to high concentrations of these toxicants, posing a hazard to this and other species that inhabit the area $3,4,5,6,7,8,9,10$.

When evaluating the risks of exposure to a contaminant for any species, it is desirable to count earlyresponse biomarkers capable of anticipating irreversible damage that may occur at later stages of development ${ }^{11}$. Molecular targets, effectors or modulators of toxicant effects are among early-response biomarkers. However, their development in autochthonous, nonmodel species such as $R$. arenarum is difficult due to the lack of both sequenced genomes that allow primer design and transcript analysis, as well as specific antibodies necessary to support protein expression analysis ${ }^{3}$. In these cases, toxicogenomic and particularly transcriptomic analyses through bulk RNA sequencing (RNA-Seq) are powerful tools that enable screening for effects and responses to a toxicant and therefore allow further molecular studies ${ }^{12,13}$. 
RNA-Seq is a highly sensitive and accurate tool for measuring expression across the transcriptome, enabling researchers to detect changes that otherwise would go unnoticed. It enables the detection of both known and new features in a single assay, uncovering isoforms, fused genes, single-nucleotide polymorphisms (SNPs), and other functional features without the limitation of prior knowledge.

Transcriptome sequencing makes it possible to obtain a genic expression profile under a given stimulus at a given moment of time. It also makes it possible to quantify the levels of abundance or relative changes for each transcript during a specific developmental stage or under a specific treatment ${ }^{14}$. In the case of nonmodel organisms such as $R$. arenarum, RNA-Seq technology allows the obtention of genomic information through a relatively accessible process from an economic point of view and considering the cost-benefit relationship ${ }^{13}$.

In the context of RNA-Seq and transcriptomic analysis performed on $R$. arenarum larvae exposed to the organophosphorus (OP) pesticides azinphos-methyl (AZM) and chlorpyrifos (CPF) ${ }^{13}$, we performed hypothesis-driven data analysis processing on a priori selected mRNA transcripts. The aims of the study were a) to compare transcript expression levels in genes from pathways that have been previously recognized as impacted by OP pesticides and that have also been studied at the biochemical, metabolite or physiological level in $R$. arenarum to obtain a more comprehensive mechanism of toxicity and response and $\mathrm{b}$ ) to test a set of potentially adequate housekeeping genes in $R$. arenarum larval stages for future quantitative PCR studies.

\section{Materials And Methods}

\section{Chemicals}

High purity-certified standards of azinphos-methyl (98.3\% AZM) and chlorpyrifos (CPF; 99.5\% purity) were purchased from Chem Service Inc. (West Chester, PA, USA). Standard solutions of $18 \mathrm{~g} \mathrm{~L}^{-1} \mathrm{AZM}$ and $1 \mathrm{~g} \mathrm{~L}^{-}$ ${ }^{1} \mathrm{CPF}$ were prepared by dissolving the pesticide standards in acetone. The exact concentrations of AZM and CPF in the standard solution were checked by capillary gas chromatography coupled to a nitrogenphosphorus detector (GC-NPD).

\section{Biological material}

Adult females and males of the South American common toad (Rhinella arenarum) were collected in reference areas, free of pesticide application, in agreement with the corresponding collection permission 040/2020 from the Environment Secretary of Río Negro Province, Argentina. Animals used in this study were maintained and treated with regard to the alleviation of suffering according to recommendations of the Guide for the Care and Use of Laboratory Animals (National Research Council 2011) ${ }^{55}$. The animals were kept in captivity outdoors for 24-48 h until their use. Female ovulation was induced by intraperitoneal injection of 2500 international units (IU) of human chorionic gonadotropin (ELEA Laboratory, Buenos Aires, Argentina.) and embryos were obtained by in vitro fertilization ${ }^{5}$. Embryos were 
maintained until they reached the complete operculum (CO) stage (stage 25 , according to ${ }^{56}$ ). Ten days after reaching the $\mathrm{CO}$ stage, the larvae were used for acute toxicity assays.

\section{Acute toxicity assays}

The whole protocol was approved by the Faculty Committee for Care and Use of Experimental Animals (CICUAL- Facultad de Ciencias Agrarias Universidad Nacional del Comahue 01/13- 7 -2020). Larvae were randomly collected to perform the assays. Sublethal concentrations of AZM $\left(0.5 \mathrm{mg} \mathrm{L}^{-1}, 1 / 2096 \mathrm{~h}-\right.$ LC50; ${ }^{4}$ ) and CPF $\left.\left(0.1 \mathrm{mg} \mathrm{L}^{-1}\right), 1 / 1596 \mathrm{~h}-\mathrm{LC} 50 ;{ }^{8}\right)$ were selected to carry out exposures for up to $24 \mathrm{~h}$ in glass dishes, maintaining a ratio of 1 larva/ $10 \mathrm{~mL}$ in amphibian Ringer's solution with $0.3 \%$ acetone (final $\mathrm{v} / \mathrm{v}$ ). The exact pesticide concentrations were checked by gas chromatography and nitrogen-phosphorus detection. Control acetone treatment was included to discard possible solvent effects. The treatments were carried out in duplicate, and $R$. arenarum larvae were grown in 10 different glass receptacles to perform AZM/CPF $6 \mathrm{~h}$ exposures, AZM/CPF $24 \mathrm{~h}$ exposures, and control treatments. From each receptacle, fifteen random larvae were collected and pooled at the corresponding times. Larvae were washed three times with cold Ringer's solution, placed in $1.5 \mathrm{~mL}$ tubes with RNALater ${ }^{\circledR}$ (Thermo Fisher Scientific Inc.) and stored at $-20^{\circ} \mathrm{C}$ until processed.

\section{RNA extraction, cDNA library generation and massive parallel sequencing}

RNA extraction, cDNA library generation and massive parallel sequencing were carried out as described by Ceschin et al. $(2020)^{13}$. Briefly, total RNA of each sample was extracted, and the cDNA library for transcriptome analysis was prepared. The ten library samples were normalized to $10 \mathrm{nM}$ cDNA to be sequenced on a HiSeq 1500 Illumina platform, generating nonstrand specific "paired-ends" (PE) $2 \times 100$ bp readings.

\section{Statistical analysis of expression levels}

The readings obtained by massive sequencing of the $R$. arenarum transcriptome were aligned with Bowtie2 v2.3.5 ${ }^{57}$ against TSA: GHCG00000000.1 (BioProject PRJNA485066), and transcript expression quantification was performed using RSEM v1.3.0 ${ }^{58,59}$. Expression values were normalized by the TMM method using the $\mathrm{R}$ and EdgeR packages ${ }^{60,61}$. Once the adequate $\mathrm{HK}$ transcripts were identified, the TMM values were standardized both by the average of the selected reference genes and by the respective control values. Finally, a nonparametric analysis was performed by the median and Kruskal-Wallis tests to assess significant differences or tendencies using the exact p-values. Raw data, standardization steps and statistical analyses are available in Supplementary file II.

\section{Results}

Gene selection from annotated transcripts for OP effect analysis. 
We used a list of the available gene transcripts in $R$. arenarum published by us in the database from massive RNA transcript sequencing and gene annotation (http://rhinella.uncoma.edu.ar/; ${ }^{13}$ ). We selected a group of 14 potential housekeeping genes, considering those currently proposed for mRNA expression normalization in Xenopus laevis ${ }^{15,16,17}$ (Table S1, GROUP A). We found a considerable number of annotated genes that could be included in the following pathways, which were selected on the basis of available information about $\mathrm{OP}$ effects at the biochemical level in amphibians ${ }^{6,8,18}$ and other vertebrates: polyamine metabolism genes, (Group B, 14 genes); antioxidant response genes (Group C, 16 genes); OPmetabolizing, primary- and secondary-target enzyme genes (Group D, 16 genes); and gene expression regulators, transcription factors and phosphorylation cascade effectors corresponding to the MitogenActivated protein kinase pathway, Transcription factor AP-1, Aryl hydrocarbon receptor (AHR) pathway and Nuclear factor erythroid 2-related factor 2 antioxidant response pathway (Group E, 17 genes) (Figure 1). The complete list of genes is detailed in Supplementary Table S1.

\section{Corroboration of gene annotation for selected transcripts}

Alignments were carried out using the tools available in BLAST (BLASTN, BLASTX and BLASTP) to verify that the sequences of the selected transcripts effectively corresponded to the annotated genes. Those sequences that yielded a match greater than $50 \%$ in the vertebrate databases were selected for further analysis. A summary of this sequence validation is shown in Figure 1, and the complete analysis is available in Supplementary File I. From a total of 225 transcript sequences that were compared to the corresponding annotated genes, $93.8 \%$ could be effectively confirmed for further analysis; the best correspondence was obtained in group E covering transcription factors and signaling pathways with a $100 \%$, and the lowest percentage was approximately $90 \%$ for the group of antioxidant stress transcripts (Group C).

\section{Validation of adequate transcription levels for filtered transcripts}

Previously validated transcripts were analyzed to determine if the transcription levels of treatment replicates were appropriate for statistical analysis. These levels resulted from the massive RNAseq amplification and quantitation of each transcript fragment in the different treatments. As 'not appropriate' levels, we considered fragments with zero expression levels in any sample and/or replicates with very low and erratic values. The summary of transcripts accepted in each group of selected genes is shown in Figure 1. The raw data corresponding to all transcript fragments are available in Supplementary File II.

\section{Housekeeping genes stability}

We carried out a transcription stability analysis of the selected potential housekeeping genes, comparing their variability within and between the treatments. The respective TMM means, minimum and maximum expression values, standard deviations, median expressions and percentual coefficients of variation (CV\%) are presented in Table 1. We assumed a maximum CV\% of $20 \%$ in the TMM as an acceptable limit for a transcript to be considered housekeeping. In this way, we were able to select 9 out of 12 transcripts 
as appropriate reference genes in the first larval stage of $R$. arenarum. The genes with the least and acceptable variations in group A were EF1A0, EF1GA, EF1D, EF1B, TBA, TBB, TBB4B, ACTB, and RL8.

The transcripts belonging to tubulin TBA1 and glyceraldehyde 3P dehydrogenase (G3P) showed a variability of approximately $22 \%$ in their expression levels, roughly in the exclusion limits we considered, and might be considered housekeeping genes if a refined and specific analysis proves better results. In turn, ACT3, belonging to sarcomeric actin, showed the greatest variation in expression at $83 \%$, clearly indicating that it cannot be considered a housekeeping gene in $R$. arenarum larvae, at least for OP pesticide studies. The TMM values of the selected HKs, rated with respect to their control values, were averaged for each treatment and used to standardize the TMM values of the transcripts corresponding to the genes of groups B, C, D and E (raw and standardized data shown in Supplementary file II).

\section{Effects of OP on the transcription of polyamine metabolism genes}

OP mainly decreased the expression of genes related to polyamine synthesis (Figure 2A). Although some differences could be noted between CPF and AZM and the exposure times, decreases reaching $30-40 \%$ in the expression levels were found in ornithine decarboxylase (DCOR1), S-adenosylmethionine decarboxylase proenzyme (AMD, transcript 1-b), spermidine synthase (SPEE), and ornithine decarboxylase antizyme (OAZ1). Only AMD transcript 1-a showed relevant increases of nearly 3 times the control values when exposed to both OP pesticides. In turn, the ornithine decarboxylase regulator OAZ2 and the antizyme inhibitors AZIN1 and 2 showed no significant or no relevant changes (Supplementary Table S2).

In turn, polyamine-degrading enzymes showed more variable responses to OP pesticides (Figure 2B). AOC1 transcript expression, corresponding to diamine oxidase, showed a significant inhibition of $60-75 \%$ by AZM treatment and $50-70 \%$ by CPF treatment. The AOC2 transcript showed a similar tendency with even deeper inhibition responses, but the difference was not significant (Table S2). AOC3 and 4 transcript isoforms showed variable and nonsignificant responses to OP pesticide exposure. Acetyl

spermidine/spermine oxidase (PAOX) expression showed an induction tendency of $40 \%$ with both OPs at $6 \mathrm{~h}$ of exposure, while spermine acetylase transcript expression (SAT1, 2-a, 2-b) showed an inhibitory trend with CPF up to $40 \%$. Spermine oxidase expression was scarcely inhibited $(20 \%)$ by AZM and induced by CPF $(20 \%, 6 \mathrm{~h})$ (Figure 2B).

\section{Effects of OP on oxidative stress response - antioxidant enzyme genes}

Superoxide dismutase transcripts displayed differential responses to OP treatments (Figure 3A). SODC expression showed a decrease in response to AZM exposure at $24 \mathrm{~h}$ and to CPF at 6 and $24 \mathrm{~h}$ of exposure (up to $30 \%$ inhibition) with respect to the control. SOD3 was less affected, as its transcription was significantly inhibited by approximately $25 \%$ by AZM at $24 \mathrm{~h}$ and CPF at $6 \mathrm{~h}$ of exposure. On the other hand, SODE expression was significantly induced in $60 \%$ by CPF at $24 \mathrm{~h}$. Catalase transcription (CATA) was in turn slightly inhibited by AZM exposure at $24 \mathrm{~h}$ and by CPF up to $25 \%$. 
Glutathione-dependent peroxidase transcripts were mainly induced by OP pesticides. GPX1 transcription was considerably induced by AZM at $24 \mathrm{~h}(3 \mathrm{X})$ and by CPF at both times (up to 2.7X). GPX3 transcription was induced to a lesser extent but in a significant way by CPF (1.5X), while GPX4 also showed an induction of approximately $30 \%$ by CPF exposure. In turn, the transcript corresponding to GPX8B presented a tendency to decrease in samples exposed to AZM at 24 and to CPF at 6 and $24 \mathrm{~h}$, up to $60 \%$ with respect to the control. Two other GPX transcripts, GPX2 and 7, as well as one GSH-reductase transcript (GSHR), showed decreasing but not significant trends due to OP pesticide exposure (Supplementary Table S2). Finally, one transcript for the enzyme glutathione synthetase (GSHB) was scarcely downregulated by OP exposure (AZM at $24 \mathrm{~h}$; CPF at both times, approximately 25\%) (Figure 3B).

\section{OP pesticide targets and detoxifying enzymes}

Although some fragments corresponding to cholinesterase transcripts were detected (BCHE), their levels were very low and showed erratic responses (raw data in Supplementary file II). Among the esterase group, carboxylesterase (EST5A) transcript showed a relevant decrease in larvae exposed to AZM at both 6 and $24 \mathrm{~h}$, while in larvae exposed to CPF, a decrease at $6 \mathrm{~h}$ (50\% inhibition) was observed, returning to control values at $24 \mathrm{~h}$ (Figure 4A). A similar pattern was observed for another carboxylesterase transcript (EST3B), with no significant effects (Supplementary Table S2). The serum paraoxonase/arylesterase-2 transcript (PON2) showed a small but significant decrease of approximately $20 \%$ only in larvae exposed to $\mathrm{CPF}$ at $6 \mathrm{~h}$ with respect to the controls. For cytochrome P450 enzymes, only the transcripts putatively related to OP metabolization were analyzed; CYP1A1 transcript expression was significantly reduced by AZM at $24 \mathrm{~h}$ and by CPF exposure, although the effects were minor (20\% inhibition). Cytochrome CYP2C19 expression was more markedly inhibited by both OP pesticides after $6 \mathrm{~h}$ of treatment, reaching $50-60 \%$ inhibition with respect to controls.

Glutathione-S-transferase (GST) transcripts were among the most abundant groups, as 15 different isoforms could be identified. The GST isoforms alpha (GSTA3), pi (GSTP1 and 2), and theta (GSTT3) were downregulated by both OP pesticides, with transcription inhibitions ranging from 20 to $50 \%$ with respect to controls (Figure 4B). Isoform GSTP1 showed the highest inhibition and in a significant way. Although GST Mu (GSTM1) showed a decreasing trend, the effects were not significant (Table S2). On the other hand, GST Kappa 1 transcript (GSTK1) was significantly induced by CPF (45\%), while GSTM3 showed the highest transcription induction values by CPF and by AZM at $24 \mathrm{~h}$, reaching $2 \mathrm{X}-3.3 \mathrm{X}$ expression values with respect to controls, but with a p-value of 0.09 . The GST omega 1 transcript (GST01) also showed a significant increase of $45 \%$ in its expression for AZM at $6 \mathrm{~h}$ and CPF at $24 \mathrm{~h}$.

Microsomal GST transcripts were also analyzed, finding increases in the expression levels of isoforms 1, 2 and 3 (M-GST1, M-GST2, M-GST3, respectively, Figure 4C). The M-GST1 transcript was one of the most affected transcripts, with increases of 40\% (AZM-24 h; CPF-6 h) to 70\% (CPF-24 h). One M-GST3 transcript showed roughly similar effects (30-60\% increase), while a second transcript showed a moderate increase (20\%) only for CPF at $24 \mathrm{~h}$ of exposure. For the M-GST2 isoform, we also identified 
two transcripts, one of which showed a moderate increase (up to 35\%) after CPF exposure, and the other showed slight decreases of approximately $20 \%$ in its expression with respect to the controls.

\section{OP effects on transcription factor- and signaling pathway-related genes}

The MAP kinase phosphorylation pathway seemed to be affected solely at the first level of regulation, as mitogen-activated protein kinase kinases (MP2K) were downregulated early by CPF at $6 \mathrm{~h}$ and late by AZM at $24 \mathrm{~h}$ (Figure 5); the MP2K2 transcript was diminished to $70 \%$ by both OP pesticides, while the MP2K1 transcript was affected only by CPF but not at a relevant level (Supplementary Table S2).

Similarly, the mitogen-activated protein kinase p38 transcript was scarcely affected by both OP pesticides (approximately 12\%), while the JUNK transcript remained unaffected. None of the transcription factor JUN transcripts detected (JUN-1, JUN-B, JUN-D1) were significantly affected by OP exposure (Table S2). In turn, the transcription factor FOS, which associates with JUN as a heterodimer partner in activator protein-1 (AP1), showed a severe reduction in its transcription levels by AZM at $6 \mathrm{~h}$ of exposure (to $35 \%$ of control levels) but recovered at $24 \mathrm{~h}$ and surpassed controls by $25 \%$; CPF caused an inverse pattern, inducing transcription of FOS at $6 \mathrm{~h}(40 \%)$ but inhibiting it at $24 \mathrm{~h} \mathrm{(30 \% )} \mathrm{(Figure} \mathrm{5).}$

On the other hand, nuclear factor erythroid 2-related factor 2 (NRF2), linked to the antioxidant response through the antioxidant response element (ARE) pathway, showed a decrease in transcription of approximately $30 \%$ in the larvae exposed to AZM for $24 \mathrm{~h}$ and in those exposed to CPF for 6 and $24 \mathrm{~h}$ compared to controls (Figure 5).

Within the aryl hydrocarbon receptor (AhR) pathway, some differences were found for the nuclear translocator (ARNT) and the aryl receptor repressor (AHRR). Two transcripts for ARNT were analyzed. The first ARNT transcript showed a decrease of nearly $30 \%$ in larvae exposed to AZM at $24 \mathrm{~h}$ and to CPF at 6 and $24 \mathrm{~h}$ compared to the controls. The second transcript, ARNT2, showed a relevant induction in transcription of nearly $2 \mathrm{X}$ after $6 \mathrm{~h}$ of exposure to CPF. The AHRR transcript showed an increase in larvae after $24 \mathrm{~h}$ of exposure to AZM (80\%) and CPF (40\%) at $24 \mathrm{~h}$ with respect to the controls. The AhR transcript itself showed a decreasing but statistically nonsignificant pattern after exposure to CPF (Table S2). The transcript corresponding to HSP90AB1, the chaperone that binds AhR in the cytosol, showed a decrease of $20 \%$ after $24 \mathrm{~h}$ of exposure to CPF, while the transcript corresponding to the cochaperone aryl-hydrocarbon-interacting protein-like-1, AIPL1, was downregulated by AZM (approximately 50\%) but increased by CPF (up to 75\%). Another isoform, AIP, showed no effects, as well as the third cochaperone prostaglandin E synthase-3, PTGES3.

\section{Discussion}

We succeeded in applying a hypothesis-driven transcript analysis from a transcriptome database on $R$. arenarum larvae exposed to two OP pesticides, with two purposes into mind: 1) to test HK genes currently used in model species and 2) to compare the effects of AZM and CPF on transcript levels for pathways previously described as impacted at biochemical or protein expression levels. These goals in a native, nonmodel species such as the amphibian $R$. arenarum are a very good example of what transcriptomics 
analysis can do, solve or imply for the advance in molecular toxicology when other tools are not readily available $12,19,20$. Considering the results obtained, it is evident that the transcriptomic expression data allow a screening analysis into selected pathways to decide for further qPCR studies if necessary. Furthermore, we can confirm that transcriptomic information is an essential tool when developing molecular biology assays in nonmodel organisms.

One of the problems in gene transcription analysis is being able to accurately determine the amplification degree of the nucleic acid present in the reaction. This is commonly achieved using HK genes, that is, those genes constitutively expressed and consequently not affected by the exposure conditions. In a comprehensive study conducted with Xenopus laevis, RL8 and GAPDH were stable as reference genes during the first embryonic stages, ODC1 was stable in the initial and final stages, and $\mathrm{H} 4$ was adequate throughout embryonic development ${ }^{15}$. In another study in $X$. laevis, eEF1A1 and SUB1 L were identified as the genes whose expression remained more stable, which would allow their use as reference genes ${ }^{16}$. In this work, we were able to analyze the expression levels of potential reference genes from the $R$. arenarum transcriptome data considering those proposed for $X$. laevis, selecting a list of 9 genes that would fit to the different requirements in future qPCR studies. We confirm that RNA-Seq data have the potential to identify genes with less variation in their expression, as suggested by other authors $21,22,23$.

By analyzing the transcriptomic data of selected pathways of $R$. arenarum larvae exposed to the OP pesticides AZM and CPF, we obtained an overview of their regulatory effects on gene transcription at previously known targets. A qualitative representation of a reduced heatmap is shown in Figure 6. This method of representing transcription level data enables a rapid comparison among the different treatments or states ${ }^{12}$. The first conclusion to be highlighted is that, in general, the exposure of $R$. arenarum larvae to AZM or CPF at sublethal concentrations and up to $24 \mathrm{~h}$ did not cause notable changes in gene expression in the selected pathways. This is very interesting, considering that target esterase genes, detoxifying genes and oxidative stress response genes might be a priori expected to be upregulated, as their protein products are either inactivated by OP pesticides or their activities are engaged in xenobiotic transformation and detoxification 24,25,26,27. Most of the transcripts showing changes in their levels after OP exposure did so in a moderate way, and only a few showed fold-changes higher than 2X. Thus, moderate changes in mRNA expression in these genes would be enough for ample response changes in their product activities. Another observation is that exposure to AZM clearly provokes a relatively poor effect on the genes analyzed at the short exposure time of $6 \mathrm{~h}$; AZM effects are mainly evident after $24 \mathrm{~h}$ of exposure. This may be seen in all the selected groups, except for polyamine metabolism genes, where most of their expression levels were altered. In turn, the CPF effects on $R$. arenarum were more potent, affecting most of the gene expression early at $6 \mathrm{~h}$ and sustaining the effects after $24 \mathrm{~h}$ of exposure. Another interesting feature to be taken into consideration is that downregulation cases notably exceed induction cases, in a proportion of 3 to 1 .

The polyamine metabolism pathway was probably the most affected group of those analyzed in this work, as shown in Figure 6. The general pattern of the effects of both OP pesticides on polyamine 
synthesis suggests downregulation through successive involved genes. Ornithine decarboxylase, Sadenosyl methionine decarboxylase precursor and spermidine-spermine synthase expression were mainly inhibited, except for one AMD-1 transcript that showed an induction reaching 2-fold or more. Antizyme expression is also inhibited, but this may be a feedback effect due to ODC inhibition itself.

Complementary to these effects on polyamine synthesis, degradation genes tend to be downregulated by OP pesticides, probably as a cellular response intended to avoid a lethal drop in polyamine levels ${ }^{28,29,30,31}$. Nevertheless, some enzymes related to spermidine and spermine degradation show increasing expression in larvae exposed to CPF, which seems to elicit stronger effects than AZM. A decrease in putrescine and spermine was observed in $R$. arenarum embryos of the complete operculum stage exposed to AZM ${ }^{32}$. Similarly, CPF downregulated ODC activity and decreased putrescine and spermidine levels in early $R$. arenarum embryos, correlated with the percentage of embryonic developmental arrest ${ }^{18}$. The opposite effect was reported in $R$. arenarum late embryos exposed to AZM, where ODC activity and putrescine content were increased ${ }^{31}$. We also found concordance between the transcript expression levels and some of the polyamine-degrading enzymes and previously reported activity values in $R$. arenarum embryos exposed to AZM or CPF, i.e. the inhibition of DAO and SMOX activities and the increase in PAOX activity ${ }^{32}$. Therefore, there is a good correspondence between the expression levels found at the transcriptomic level for the regulatory enzymes, some of the polyaminemetabolizing enzyme activities and the polyamine contents in $R$. arenarum. On the other hand, spermidine did not show variation throughout embryonic development for AZM-exposed embryos ${ }^{32}$. These findings are related to the fine regulation of polyamine metabolism, both at the transcriptional level and at the enzymatic level. According to studies performed in the first embryonic stages in Xenopus, AMD overexpression leads to the interruption of normal embryonic development, causing cell apoptosis ${ }^{33}$. Correspondingly, the increased expression of the AMD1 transcript elicited by exposure to AZM and CPF in our work may be related to an apoptotic mechanism triggered to eliminate abnormal and damaged cells caused by pesticide exposure. On the other hand, the increase in AMD1 transcription could also be due to the need to synthesize a greater amount of spermidine. Spermidine acts as a donor of the aminobutyl group for posttranslational modifications of the lysine residue in the transcription factor elF5A. This modification is essential for the activity of the transcription factor, whose function is to contribute to transcription, nucleus-cytoplasm transport, mRNA renewal and apoptosis ${ }^{34}$.

Oxidative stress has been reported in different organisms exposed to OP pesticides. In particular, the effects of AZM and CPF on oxidative stress and antioxidant responses at the metabolite and enzymatic levels have been studied in $R$. arenarum development. Indeed, we have proposed that there is a link between OP effects on polyamine metabolism and levels, oxidative stress and teratogenic effects in $R$. arenarum embryos and larvae $5,6,7,8,18,24,31,32,35,36$. Smirnova et al. (2012) ${ }^{37}$ analyzed oxidative stress as the cause of alterations in polyamine metabolism due to the dysregulation of ODC and SSAT; human hepatoma cells chemically induced to increase ROS production showed overexpression of ODC and SSAT, which are transcriptionally regulated by NRF2 through a specific recognition site ${ }^{38}$. The downregulation of NRF2 mRNA expression with elevated Nrf2 protein levels has been reported in liver 
pathologies ${ }^{39}$. We found that OP exposure in $R$. arenarum larvae caused a downregulation of NRF2 mRNA expression, and the accompanying downregulation at the transcriptional level of ODC, SSAT and several antioxidant-detoxifying enzyme genes containing ARE sequences (such as GSTA and GSTP) suggests that Nrf2 protein or activity might also be downregulated.

Ma et al. (2018) ${ }^{40}$ refer to the alterations in transcription levels of detoxifying and oxidative stress-related enzymes in the GST and CYP groups in a transcriptomic analysis performed on trichlorfon-exposed Rana chensinensis. This OP pesticide upregulated CYP2C transcripts but downregulated CYP3A and GSTK1. We report an increase in GSTK1 expression because of CPF exposure in $R$. arenarum, as well as for other GST isoforms, such as mu and the microsomal isoforms. This upregulation in several GST transcripts is in concordance with the reported increase in GST activity using CDNB as a substrate in $R$. arenarum embryos and larvae after exposure to both AZM and CPF, among other OP pesticides ${ }^{7,35,41}$. The effect on GST activity was associated with an increase in GST-Pi1 protein in $R$. arenarum larvae exposed to arsenic 11. Other genes under Nrf2 regulation are those belonging to antioxidant defenses, such as SOD3, glutathione peroxidases (GPx2, 3, 6 and 8), and glutathione reductases (GSHR1) ${ }^{40,42}$. Accordingly, we observed downregulated levels of SOD3 and GPX8 accompanied by NRF2 downregulation. Other SOD transcripts, glutathione synthase GSHB, and CATA, also seemed downregulated, while SODE, GPX1, 3 and 4 were induced, mainly by CPF. In our experience, the antioxidant enzymatic activity response varies greatly in $R$. arenarum embryos and larvae exposed to OP pesticides, showing cycles of induction followed by inhibition attributed to catalytic site inactivation due to ROS attack $8,24,35,41,43$. In the response of $\mathrm{R}$. arenarum larvae to arsenic-induced oxidative stress, we observed an increase in $\mathrm{Cu} / \mathrm{Zn}$ SOD protein, followed by a decrease together with a decrease in CAT protein, with similar enzymatic activity patterns ${ }^{11,44}$.

We also report here the downregulation of CYP1A1 and CYP2A19 for both AZM and CPF exposures, probably as a negative regulation after a previous detoxification response. CYP1A1/2 are among the genes regulated by the AhR pathway by the binding of activated and nuclear-translocated AhR-Arnt heterodimeric transcription factor to DRE/XREs in their regulatory sequences. The AhR protein is currently stabilized in the cytosol by the binding of the heat-shock protein HP90AB1 as a chaperone, together with the X-associated protein AIP and the prostaglandin E3 synthase PTGES3; once activated by planar aromatic hydrocarbon binding, it translocates to the nucleus, where it binds to the nuclear translocator Arnt. There is also an AhR repression mechanism involving protein-protein interactions with AHRR ${ }^{45,46}$. Studies carried out with Sparus aurata exposed to PCBs have shown a different expression pattern between AHRR and AhR-ARNT, in accordance with those studies that suggest that multiple mechanisms can contribute to the downregulation of $A h \mathrm{R}^{47}$. Our findings coincide with these studies, as we observed induced levels of AHRR, while the levels of ARNT were decreased in $R$. arenarum larvae exposed to both CPF and AZM. Furthermore, the decreased levels of AhR-ARNT are consistent with the decreased expression found in CYP1A, since the entire mechanism is downregulated. A decrease in HSP90 and AIP transcripts, supposing reduced chaperone levels, would also contribute to lower AhR protein levels ${ }^{48}$. The AhR pathway is also involved in paraoxonase-1 expression regulation, according to results on exposure to 
polyphenols and specific inducing ligands ${ }^{49}$. In turn, the PON-2 gene has at least a CRE regulatory sequence for AP-1 regulation linked to the oxidative response and JNK activation and a PAPR-regulated site related to polyphenol activation and MEK pathway downregulation by phosphorylation ${ }^{50,51}$. Our results agree with downregulated MEK (MP2Ks), AP-1 (cFOS) and AHR pathways causing PON2 transcript repression in $R$. arenarum larvae exposed mainly to CPF. Similarly, the xenobiotic/endobiotic detoxifying carboxylesterase family (CES) is transcriptionally regulated by a series of nuclear factors and pathways: AhR, constitutive androstane receptor (CAR), pregnane $X$ receptor (PXR) and Nrf2 are involved mostly in the upregulation of some of these families ${ }^{52}$. Although we were not able to annotate putative transcripts corresponding to CAR and PXR pathways in our $R$. arenarum transcriptome, the downregulation trends followed by AhR and Nrf2 pathways in larvae exposed to AZM and CPF are in line with CES5A transcript downregulation. This may be surprising, in the sense that carboxylesterases are recognized suicide "buffer" enzymes that irreversibly react with OP pesticides to protect the primary target acetylcholinesterase in the nervous system, decreasing their activities. This is in fact corroborated in toad embryos and larvae exposed to different OP pesticides, including AZM and CPF, in most of our reports in $R$. arenarum ${ }^{3,7,8,35,53}$. Thus, an induction of carboxylesterase and cholinesterase mRNA and/or protein synthesis would be expected to reestablish normal activity levels. Finally, remarking on the complexity of the responses and crosstalk between pathways, we have reported for different developmental states in $R$. arenarum and cell cultures exposed to CPF, other OP pesticides or arsenic, an increase in MEK $1 / 2$ and ERK1/2 proteins, their translocation to the nucleus, and ERK phosphorylation, considering that the MAP kinase pathway regulates the Nrf2-mediated response. Additionally, cFOS and cJUN proteins are increased after oxidative stress in $R$. arenarum embryos and larvae ${ }^{43,44,54}$.

\section{Concluding remarks}

In conclusion, we acknowledge the power of a hypothesis-driven transcriptomic data analysis on selected pathways. First, we identified an appropriate battery of potential housekeeping genes in $R$. arenarum larvae to further analyze gene expression by conventional or quantitative PCR after pesticide exposure. Second, we were able to visualize the effects of two OP pesticides in a priori selected metabolic and signaling pathways and compare them to previous metabolite and enzyme activity analyses. In our analysis, we infer a gradient of effects since CPF is more potent than AZM and acts earlier on gene transcription. Finally, we found a prevailing downregulation in signaling cascades and transcription factors that act upstream of the polyamine metabolism pathway and antioxidant responses, which partially coincides with previously well-characterized responses at the protein and/or activity and metabolite levels.

\section{Declarations}

\section{Acknowledgments}

This work was supported by Grant 04A134 from the Universidad Nacional del Comahue and PICT 20171529 from Agencia Nacional de Promoción Científica y Tecnológica. 


\section{Competing interests statement}

The authors have no competing interests to declare.

\section{Author contributions}

NSP performed annotated gene data mining for selected pathways, statistical analyses and initial writing; CIL collaborated with experimental procedures, data calculations, manuscript revision and language editing; DGC performed the experiments, sample processing, RNAseq and bioinformatic data assembly, including gene annotation; AV contributed to project design, gene selection, data calculation, statistical analysis, manuscript writing and processing. CIL, DGC and AV are staff researchers of CONICETArgentina.

\section{References}

1. Kwet, S. R., Silvano, D., Úbeda, C., Baldo, D. \& Tada, I. Di. Rhinella arenarum. IUCN 2011. IUCN Red List Threat. Species. http//www.iucnredlist.org/apps/redlist/details/54576/0 8235, (2004).

2. Loewy, R. M., Monza, L. B., Kirs, V. E. \& Savini, M. C. Pesticide distribution in an agricultural environment in Argentina. J. Environ. Sci. Heal. - Part B Pestic. Food Contam. Agric. Wastes (2011) doi:10.1080/03601234.2011.592051.

3. Venturino, A. et al. Biomarkers of effect in toads and frogs. Biomarkers 8, 167-186 (2003).

4. Ferrari, A., Anguiano, O. L., Soleño, J. \& Pechen D'Angelo, A. M. Different susceptibility of two aquatic vertebrates (Oncorhynchus mykiss and Bufo arenarum) to azinphos methyl and carbaryl. 139, 239243 (2004).

5. Ferrari, A. et al. Changes in the antioxidant metabolism in the embryonic development of the common South American toad Bufo arenarum: Differential responses to pesticide in early embryos and autonomous-feeding larvae. J. Biochem. Mol. Toxicol. (2008) doi:10.1002/jbt.20236.

6. Lascano, C. I., Sotomayor, V., Ferrari, A. \& Venturino, A. Alteraciones del desarrollo embrionario, poliaminas y estres oxidativo inducidos por plaguicidas organofosforados en Rhinella arenarum. Acta Toxicológica Argentina 17, 8-19 (2009).

7. Rosenbaum, E. A. et al. Response of biomarkers in amphibian larvae to in situ exposures in a fruitproducing region in North Patagonia, Argentina. Environ. Toxicol. Chem. 31, 2311-2317 (2012).

8. Liendro, N., Ferrari, A., Mardirosian, M., Lascano, C. I. \& Venturino, A. Toxicity of the insecticide chlorpyrifos to the South American toad Rhinella arenarum at larval developmental stage. Environ. Toxicol. Pharmacol. 39, 525-535 (2015).

9. Guerreño, M., López Armengol, M. F., Luquet, C. M. \& Venturino, A. Comparative study of toxicity and biochemical responses induced by sublethal levels of the pesticide azinphosmethyl in two fish species from North-Patagonia, Argentina. Aquat. Toxicol. 177, 365-372 (2016).

10. Alvarez, M., Du Mortier, C., Jaureguiberry, S. \& Venturino, A. Joint Probabilistic Analysis of Risk for Aquatic Species and Exceedence Frequency for the Agricultural Use of Chlorpyrifos in the Pampean 
Region, Argentina. Environ. Toxicol. Chem. 38, 1748-1755 (2019).

11. Mardirosian, M. N., Ceschin, D. G., Lascano, C. I. \& Venturino, A. Molecular effectors in the chronic exposure to arsenic as early and sensitive biomarkers in developing Rhinella arenarum toads. Aquat. Toxicol. 186, 19-27 (2017).

12. Ceschin, D. G. Toxicogenomics: New strategies for ecotoxicology studies in autochthonous species II. the 'Omic' era in non-model species. Transcriptome analysis for biomarker screening. Int. J. Environ. Heal. 8, 213-224 (2017).

13. Ceschin, D. G., Pires, N. S., Mardirosian, M. N., Lascano, C. I. \& Venturino, A. The Rhinella arenarum transcriptome: de novo assembly, annotation and gene prediction. Sci. Rep. 10, 1-8 (2020).

14. Han, Y., Gao, S., Muegge, K., Zhang, W. \& Zhou, B. Advanced applications of RNA sequencing and challenges. Bioinform. Biol. Insights 9, 29-46 (2015).

15. Šindelka, R., Ferjentsik, Z. \& Jonák, J. Developmental expression profiles ofXenopus laevis reference genes. Dev. Dyn. 235, 754-758 (2006).

16. Verbrugghe, E., Martel, A. \& Pasmans, F. Reference Gene Validation for Quantitative Real-time PCR Studies in Amphibian Kidney-derived A6 Epithelial Cells. Altern. Lab. Anim. 47, 63-70 (2019).

17. Dhorne-Pollet, S., Thélie, A. \& Pollet, N. Validation of novel reference genes for RT-qPCR studies of gene expression in Xenopus tropicalis during embryonic and post-embryonic development. Dev. Dyn. 242, 709-717 (2013).

18. Sotomayor, V., Lascano, C., Pechen D’Angelo, A. M. P. \& Venturino, A. Developmental and polyamine metabolism alterations in Rhinella arenarum embryos exposed to the organophosphate chlorpyrifos. Environ. Toxicol. Chem. 31, 2052-2058 (2012).

19. Aardema, M. J. \& MacGregor, J. T. Toxicology and genetic toxicology in the new era of 'toxicogenomics': Impact of '-omics' technologies. Mutat. Res. - Fundam. Mol. Mech. Mutagen. 499, 13-25 (2002).

20. Venturino, A. Toxicogenomics: new strategies for ecotoxicology studies in autochthonous species I. A glade in the entangled path towards the 'fingerprint' of environmental impact? Int. J. Environ. Heal. 8, 203 (2017).

21. Stanton, K. A. et al. A whole-transcriptome approach to evaluating reference genes for quantitative gene expression studies: A case study in Mimulus. G3 Genes, Genomes, Genet. 7, 1085-1095 (2017).

22. Zhuang, H., Fu, Y., He, W., Wang, L. \& Wei, Y. Selection of appropriate reference genes or quantitative real-time PCR in Oxytropis ochrocephala Bunge using transcriptome datasts under abiotic stress treatments. 2-11 (2015).

23. Yang, $\mathrm{H}$. et al. Selection and evaluation of novel reference genes for quantitative reverse transcription PCR (qRT-PCR) based on genome and transcriptome data in Brassica napus L. Gene 538, 113-122 (2014).

24. Ferrari, A., Lascano, C. I., Anguiano, O. L., Pechen D’Angelo, A. M. \& Venturino, A. Antioxidant responses to azinphos methyl and carbaryl during the embryonic development of the toad Rhinella (Bufo) arenarum Hensel. Aquat. Toxicol. 93, 37-44 (2009). 
25. Mennillo, E., Cappelli, F. \& Arukwe, A. Biotransformation and oxidative stress responses in rat hepatic cell-line (H4IIE) exposed to organophosphate esters (OPEs). Toxicol. Appl. Pharmacol. 371, 84-94 (2019).

26. Venturino, A. \& Pechen de D’Angelo, A. M. Biochemical targets of xenobiotics: Biomarkers in amphibian ecotoxicology. Appl. Herpetol. 2, 335-353 (2005).

27. Schmitt, C., McManus, M., Kumar, N., Awoyemi, O. \& Crago, J. Comparative analyses of the neurobehavioral, molecular, and enzymatic effects of organophosphates on embryo-larval zebrafish (Danio rerio). Neurotoxicol. Teratol. 73, 67-75 (2019).

28. Bettuzzi, S. et al. Coordinate changes of polyamine metabolism regulatory proteins during the cell cycle of normal human dermal fibroblast. 18-22 (1999).

29. Schipper, R. G., Penning, L. C. \& Verhofstad, A. A. J. Involvement of polyamines in apoptosis. Facts and controversies: Effectors or protectors? Semin. Cancer Biol. 10, 55-68 (2000).

30. Thomas T. \& Thomas, T.J. Polyamines in cell growth and cell death: molecular mechanism and therapeutic applications. 244-258 (2001).

31. Lascano, C. I. et al. Organophosphorus insecticides affect normal polyamine metabolism in amphibian embryogenesis. Pestic. Biochem. Physiol. 101, 240-247 (2011).

32. Pires, N.S., Maiale, S., Venturino, A. \& Lascano, C. Differential effects of azinphos-methyl and chlorpyrifos on polyamine oxidative metabolism during the embryonic development of Rhinella arenarum and its relation to oxidative stress. Pestic. Biochem. Physiol. 163, 14-22 (2020).

33. Kai, M. et al. Overexpression of S-adenosylmethionine decarboxylase (SAMDC) in Xeno-pus embryos activates maternal program of apoptosis as a "fail-safe" mechanism of early embryogenesis. Cell Res. 13, 147-158 (2003).

34. Nishimura, K. et al. Identification of proteins whose synthesis is preferentially enhanced by polyamines at the level of translation in mammalian cells. Int. J. Biochem. Cell Biol. 41, 2251-2261 (2009).

35. Ferrari, A., Lascano, C., Pechen D'Angelo, A. M. \& Venturino, A. Comparative Biochemistry and Physiology, Part C Effects of azinphos methyl and carbaryl on Rhinella arenarum larvae esterases and antioxidant enzymes. Comp. Biochem. Physiol. Part C 153, 34-39 (2011).

36. Venturino, A. et al. Thiols and polyamines in the potentiation of malathion toxicity in larval stages of the toad Bufo arenarum. Comp. Biochem. Physiol. - C Toxicol. Pharmacol. (2001) doi:10.1016/S1532-0456(01)00241-1.

37. Smirnova, O. A. et al. Chemically induced oxidative stress increases polyamine levels by activating the transcription of ornithine decarboxylase and spermidine/spermine- N1-acetyltransferase in human hepatoma HUH7 cells. Biochimie 94, 1876-1883 (2012).

38. Ceci, R. et al. Adaptive responses of heart and skeletal muscle to spermine oxidase overexpression: Evaluation of a new transgenic mouse model. Free Radic. Biol. Med. 103, 216-225 (2017).

39. Wasik, U., Milkiewicz, M., Kempinska-Podhorodecka, A. \& Milkiewicz, P. Protection against oxidative stress mediated by the Nrf2/Keap1 axis is impaired in Primary Biliary Cholangitis. Sci. Rep. 7, 1-9 
(2017).

40. Ma, Y., Li, B., Ke, Y., Zhang, Y. \& Zhang, Y. Transcriptome analysis of Rana chensinensis liver under trichlorfon stress. Ecotoxicol. Environ. Saf. 147, 487-493 (2018).

41. Lascano, C. I., Ferrari, A. \& Venturino, A. Sublethal concentrations of azinphos-methyl induce biochemical and morphological alterations in Rhinella arenarum embryos. Chem. Ecol. 27, 557-568 (2011).

42. Vomund, S., Schäfer, A., Parnham, M. J., Brüne, B. \& Von Knethen, A. Nrf2, the master regulator of anti-oxidative responses. Int. J. Mol. Sci. 18, 1-19 (2017).

43. Sotomayor, V., Chiriotto, T. S., Pechen D'Angelo, A. M. \& Venturino, A. Biochemical biomarkers of sublethal effects in Rhinella arenarum late gastrula exposed to the organophosphate chlorpyrifos. Pestic. Biochem. Physiol. 119, 48-53 (2015).

44. Mardirosian, M. N., Lascano, C. I., Bongiovanni, G. A. \& Venturino, A. Chronic toxicity of arsenic during Rhinella arenarum embryonic and larval development: Potential biomarkers of oxidative stress and antioxidant response. Environ. Toxicol. Chem. 36, 1614-1621 (2017).

45. Evans, B. R. et al. Repression of Aryl Hydrocarbon Receptor (AHR) Signaling by AHR Repressor: Role of DNA Binding and Competition for AHR Nuclear Translocator. Mol. Pharmacol. 73, 387-398 (2008).

46. Hahn, M. E., Allan, L. L. \& Sherr, D. H. Regulation of constitutive and inducible AHR signaling: Complex interactions involving the AHR repressor. Biochem. Pharmacol. 77, 485-497 (2009).

47. Calò, M. et al. Role of AHR, AHRR and ARNT in response to dioxin-like PCBs in Spaurus aurata. Environ. Sci. Pollut. Res. 21, 14226-14231 (2014).

48. Pappas, B. et al. P23 Protects the Human Aryl Hydrocarbon Receptor From Degradation Via a Heat Shock Protein 90-Independent Mechanism. Biochem. Pharmacol. 152, 34-44 (2018).

49. Gouédard, C., Barouki, R. \& Morel, Y. Dietary Polyphenols Increase Paraoxonase 1 Gene Expression by an Aryl Hydrocarbon Receptor-Dependent Mechanism. Mol. Cell. Biol. 24, 5209-5222 (2004).

50. Shiner, M., Fuhrman, B. \& Aviram, M. Macrophage paraoxonase 2 (PON2) expression is up-regulated by pomegranate juice phenolic anti-oxidants via PPARy and AP-1 pathway activation. Atherosclerosis 195, 313-321 (2007).

51. Shiner, M., Fuhrman, B. \& Aviram, M. Paraoxonase 2 (PON2) expression is upregulated via a reducednicotinamide- adenine-dinucleotide-phosphate (NADPH)-oxidase-dependent mechanism during monocytes differentiation into macrophages. Free Radic. Biol. Med. 37, 2052-2063 (2004).

52. Zhang, Y., Cheng, X., Aleksunes, L. \& Klaassen, C. D. Transcription factor-mediated regulation of carboxylesterase enzymes in livers of mice. Drug Metab. Dispos. 40, 1191-1197 (2012).

53. Caballero de Castro, A. C., Rosenbaum, E. A. \& Pechen de D'Angelo, A. M. Effect of malathion on Bufo arenarum hensel development-I. Esterase inhibition and recovery. Biochem. Pharmacol. 41, 491-495 (1991).

54. Venturino, A. et al. Biomarkers of effect in toads and frogs. Biomarkers 8, 167-186 (2003). 
55. Guide for the Care and Use of Laboratory Animals. Guide for the Care and Use of Laboratory Animals (National Academies Press, 2011). doi:10.17226/12910.

56. Del Conte, E. \& Sirlin, J. L. Pattern series of the first embryonary stages in Bufo arenarum. Anat. Rec. (1952) doi:10.1002/ar.1091120109.

57. Langmead, B. \& Salzberg, S. L. Fast gapped-read alignment with Bowtie 2. Nat. Methods 9, 357-359 (2012).

58. Han, S., Liang, Y., Li, Y. \& Du, W. Lncident: A Tool for Rapid Identification of Long Noncoding RNAs Utilizing Sequence Intrinsic Composition and Open Reading Frame Information. Int. J. Genomics 2016, (2016).

59. Li, B. et al. Evaluation of de novo transcriptome assemblies from RNA-Seq data. Genome Biol. 15, 121 (2014).

60. Robinson, M. D., McCarthy, D. J. \& Smyth, G. K. edgeR: A Bioconductor package for differential expression analysis of digital gene expression data. Bioinformatics 26, 139-140 (2009).

61. Robinson, M. D. \& Oshlack, A. A scaling normalization method for differential expression analysis of RNA-seq data. (2010).

\section{Tables}

Table 1: Comparison of distribution statistics and expression variation of transcripts proposed as HK in $R$. arenarum stage 25 larvae. 


\begin{tabular}{|c|c|c|c|c|c|c|c|}
\hline $\begin{array}{l}\text { Gene } \\
\text { ID }\end{array}$ & Gene name & Mean & Minimum & Maximum & SD & Median & CV \% \\
\hline F1A0 & $\begin{array}{l}\text { Elongation factor } 1- \\
\text { alpha, somatic form }\end{array}$ & 7329.9 & 6610.7 & 8457.7 & 586.4 & 7265.4 & 8.00 \\
\hline EF1B & Elongation factor 1-beta & 583.4 & 498.6 & 676.9 & 64.3 & 589.4 & 11.03 \\
\hline EF1D & Elongation factor 1-delta & 922.1 & 800.7 & 1074.7 & 98.3 & 910.4 & 10.66 \\
\hline EF1GA & $\begin{array}{l}\text { Elongation factor 1- } \\
\text { gamma-A }\end{array}$ & 2993.7 & 2611.2 & 3344.1 & 252.9 & 2968.2 & 8.45 \\
\hline G3P & $\begin{array}{l}\text { Glyceraldehyde-3- } \\
\text { phosphate } \\
\text { dehydrogenase }\end{array}$ & 1822.0 & 1289.5 & 2425.1 & 411.3 & 1768.3 & 22.58 \\
\hline RL8 & $60 S$ ribosomal protein L8 & 1108.0 & 883.6 & 1309.3 & 134.8 & 1131.6 & 12.16 \\
\hline TBA & Tubulin alpha chain & 1829.9 & 1589.5 & 2014.7 & 142.9 & 1826.3 & 7.81 \\
\hline TBA1 & Tubulin alpha-1 chain & 146.1 & 98.1 & 195.5 & 31.8 & 142.1 & 21.74 \\
\hline TBB & Tubulin beta chain & 518.4 & 350.2 & 586.8 & 70.4 & 526.8 & 13.58 \\
\hline TBB4B & Tubulin beta-4B chain & 219.0 & 137.1 & 253.7 & 33.3 & 224.5 & 15.19 \\
\hline ACTB & Actin, cytoplasmic 1 & 363.6 & 301.7 & 394.4 & 37.2 & 380.3 & 10.22 \\
\hline АCT3 & $\begin{array}{l}\text { Actin, alpha } \\
\text { sarcomeric/skeletal }\end{array}$ & 90.1 & 15.1 & 259.4 & 73.3 & 61.9 & 81.27 \\
\hline
\end{tabular}

Data calculated from massive RNA-seq and transcriptomic analysis are expressed as TMM values. A limit of $20 \%$ for the CV is proposed to consider a transcript as an HK gene in expression analysis.

\section{Figures}




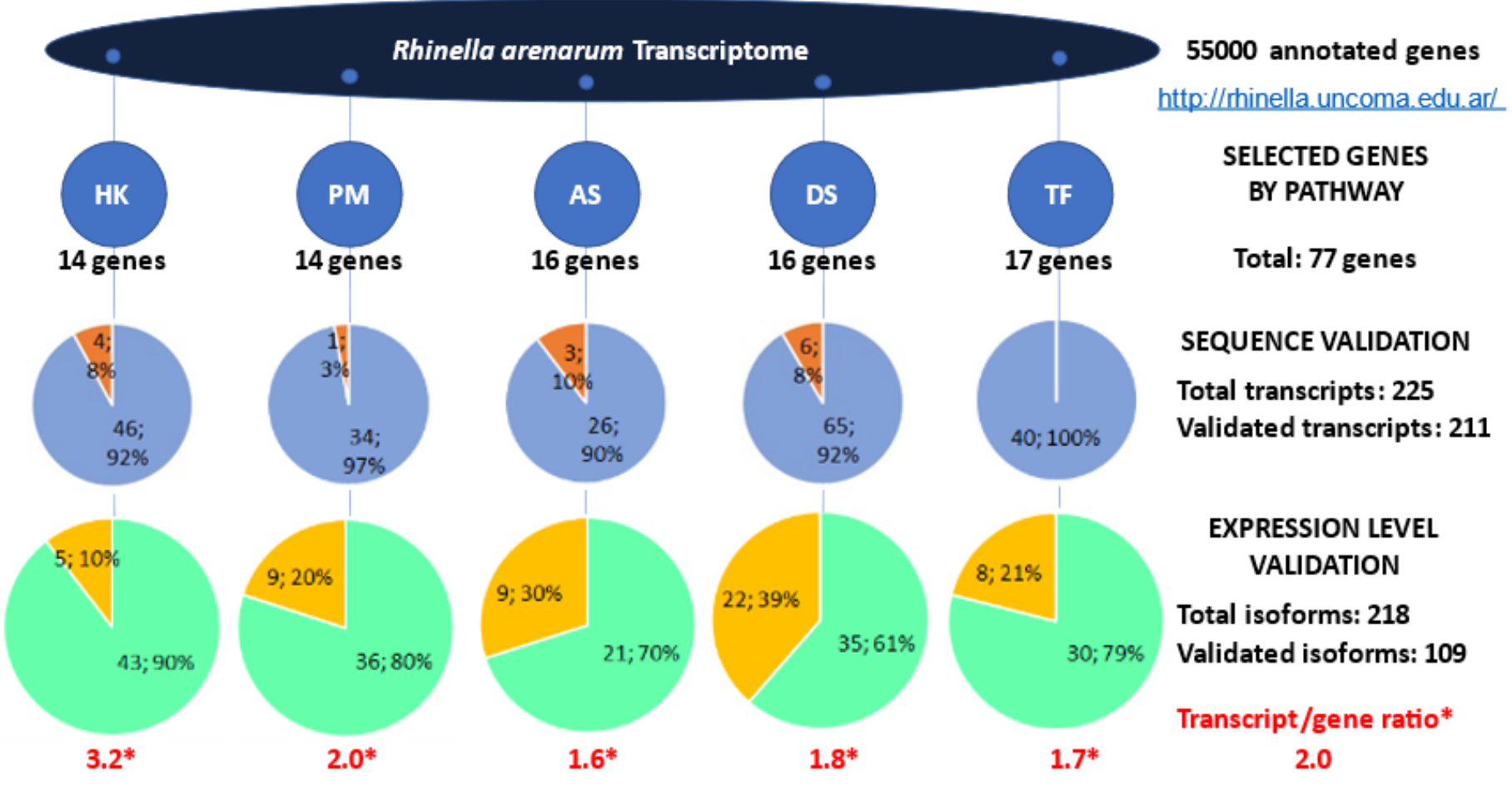

Figure 1

Gene selection process by metabolic pathway.

Hypothesis-driven selection into pathways recognized as affected by organophosphorus pesticides at enzyme activity or metabolic product levels. HK: housekeeping genes; PM: polyamine metabolism; AS: antioxidant system; DS: detoxifying systems; TF: transcription factors, signaling pathways. Once selected in a first instance, transcripts were checked by nucleotide and predicted amino acid sequence identity; afterwards, the transcription levels were checked to discard erratic low values. 

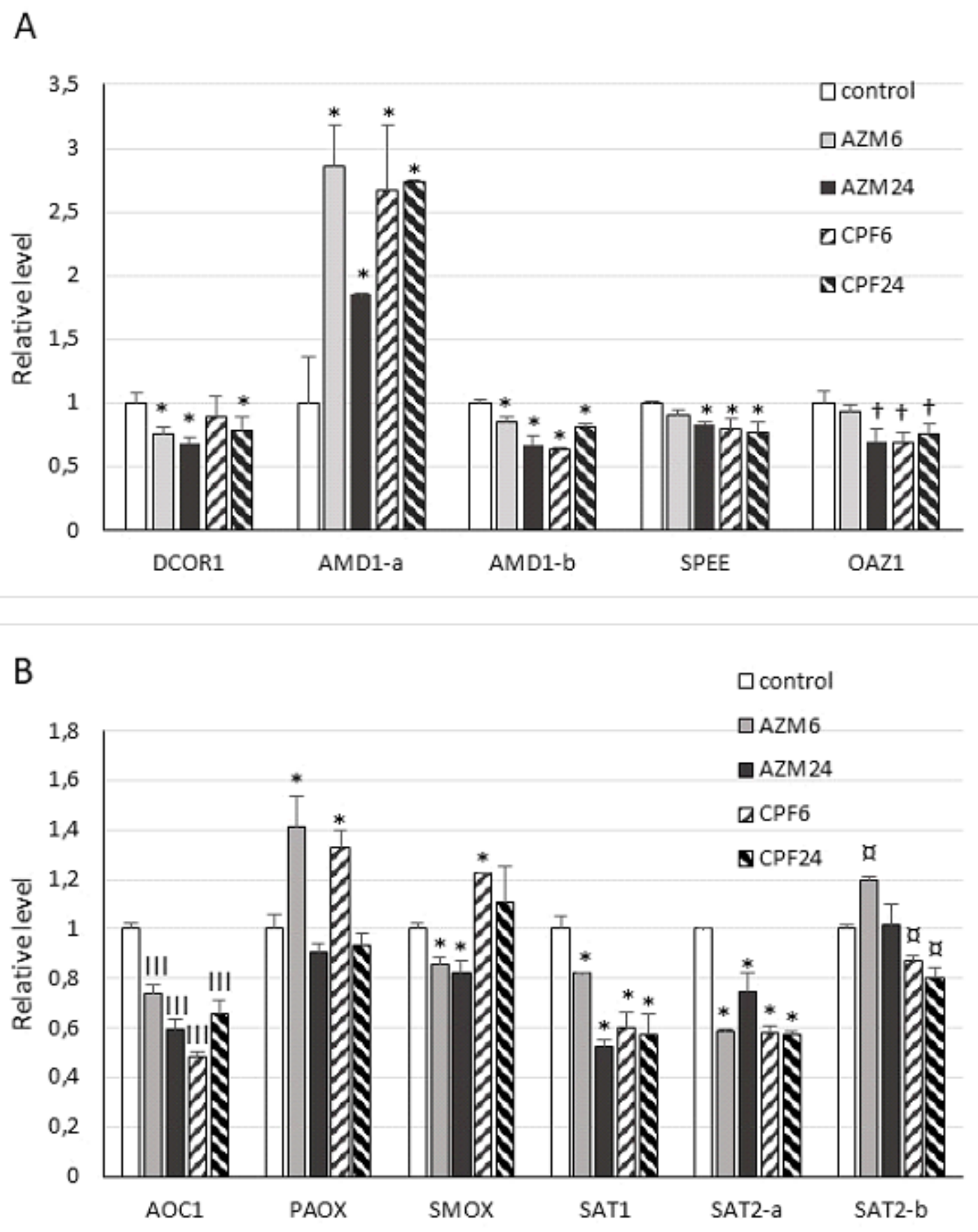

Figure 2

Expression levels of transcripts corresponding to polyamine metabolism genes in $R$. arenarum larvae. A, Genes related to polyamine synthesis and its regulation. B, genes related to polyamine degradation. Significance levels for Kruskal-Wallis and median tests, * $p=0.09$; a $p=0.08$; † $p=0.04$; III $p=0.0001$. AZM: azinphosmethyl, CPF: chlorpyrifos, at $6 \mathrm{~h}$ and $24 \mathrm{~h}$ exposures; gene codes are detailed in the text. 

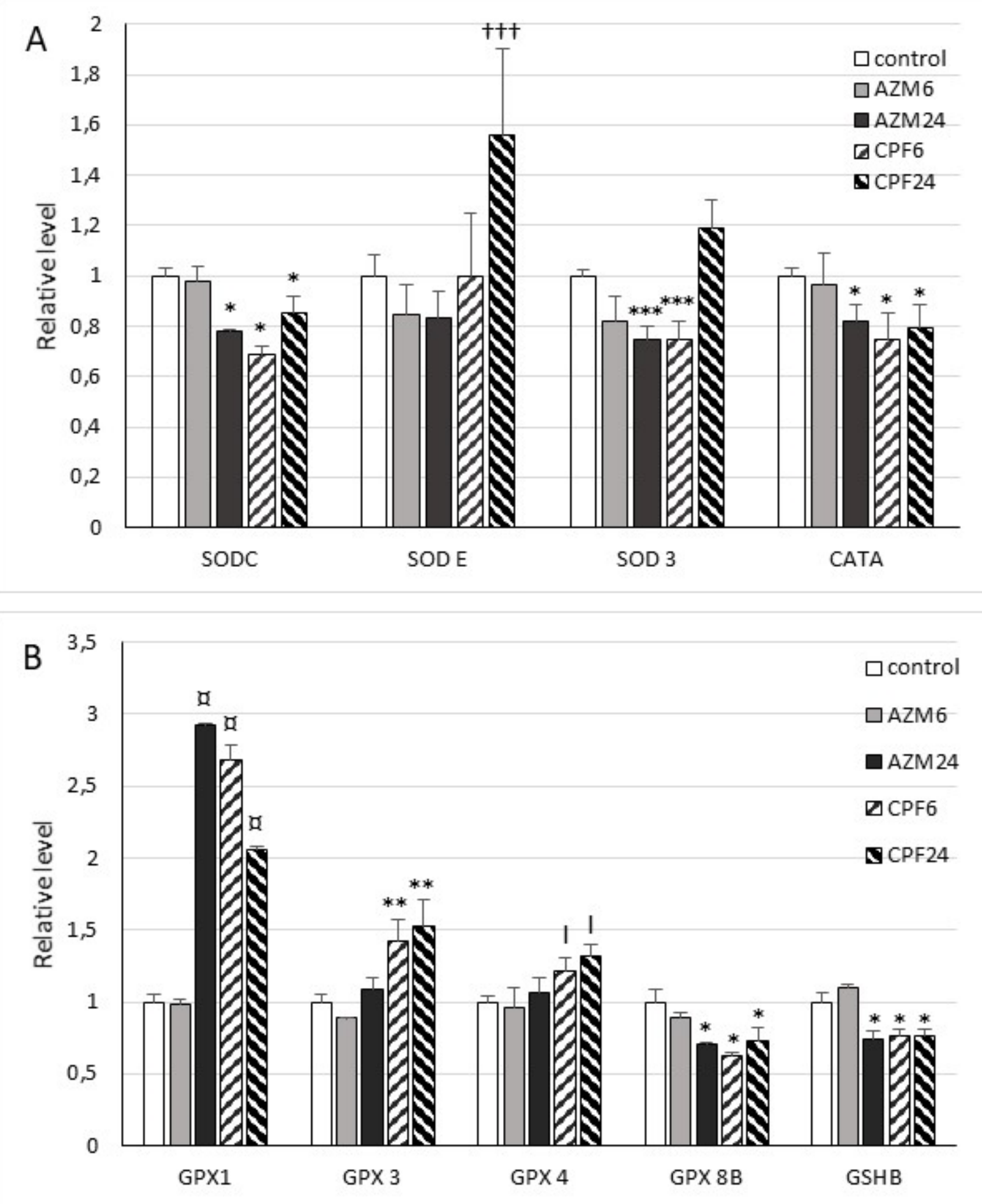

Figure 3

Expression levels of transcripts corresponding to antioxidant response genes in $R$. arenarum larvae. A, Superoxide dismutase (SOD) and catalase (CATA) genes. B, GSH-dependent antioxidant response and GSH synthesis genes. Significance levels for Kruskal-Wallis and median tests, * $p=0.09 ; a p=0.08$; I $p=0.07 ; * \star p=0.01 ; * \star \star ~ p=0.003 ;$ ††† $p=0.0007$. AZM: azinfosmethyl, CPF: chlorpyrifos, at $6 \mathrm{~h}$ and $24 \mathrm{~h}$ exposures; gene codes are detailed in the text. 

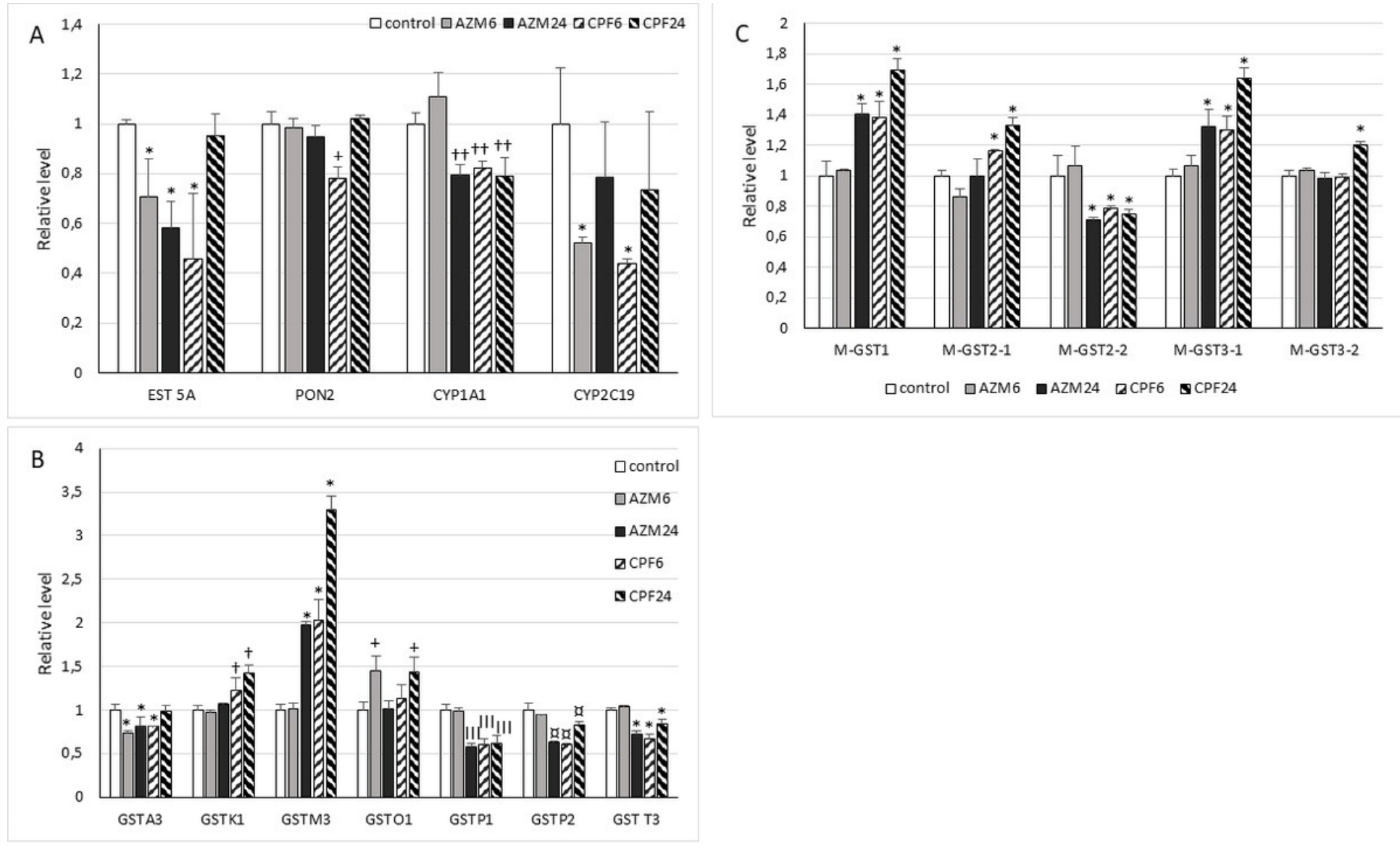

\section{Figure 4}

Expression levels of transcripts corresponding to OP-detoxifying enzyme genes in $R$. arenarum larvae. A, Esterases and Cytochrome P-450 isoforms. B, GSH-S Transferases (GST), cytosolic isoforms. C, GST, microsomal isoforms. Significance levels for Kruskal-Wallis and median tests, * $p=0.09 ; a p=0.08$; + $p=0.05 ; \uparrow p=0.04 ;+† p=0.007 ;$ III $p=0.0001$. AZM: azinphosmethyl, CPF: chlorpyrifos, at $6 \mathrm{~h}$ and $24 \mathrm{~h}$ exposures; gene codes are detailed in the text. 


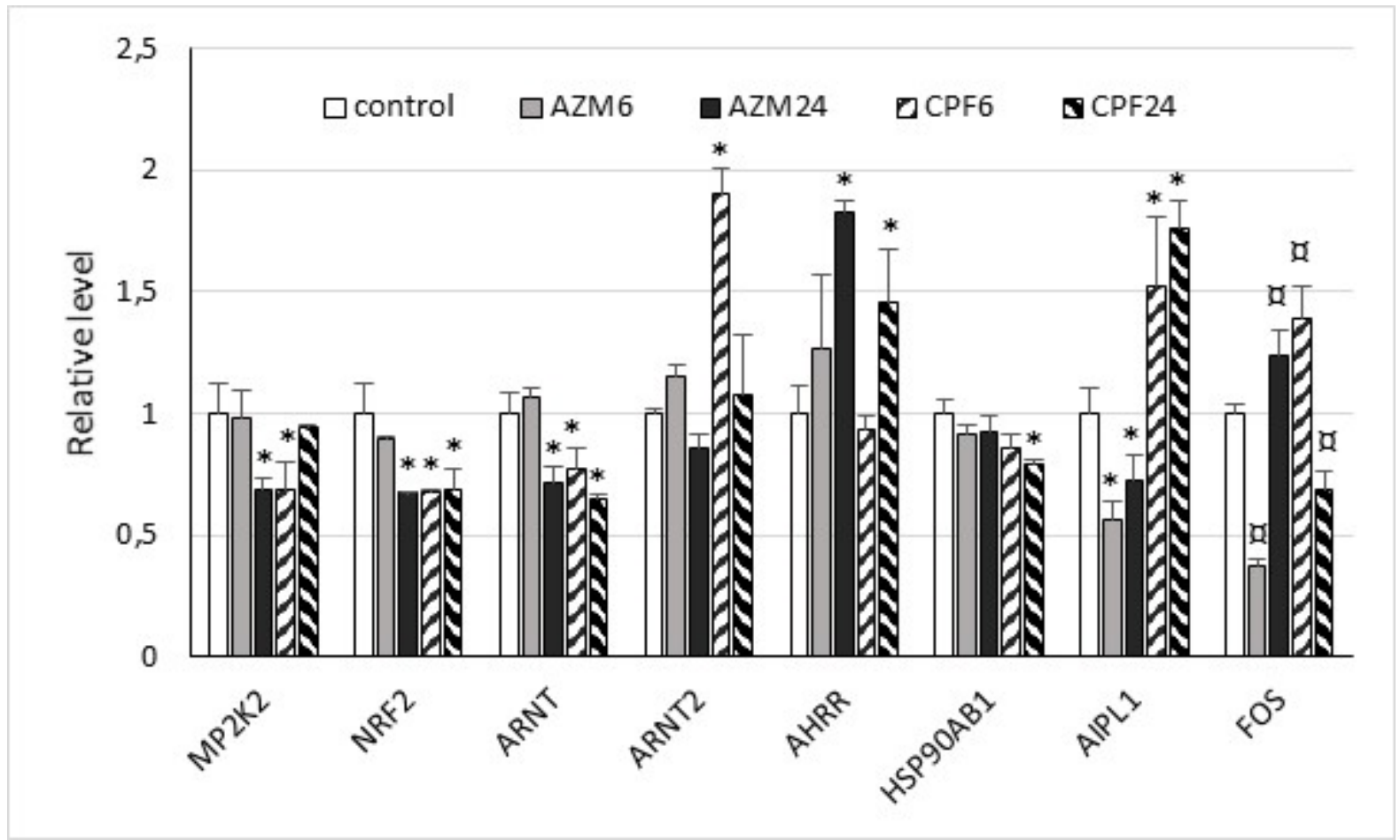

Figure 5

Expression levels of transcripts corresponding to transcription factors and signaling pathway genes in $R$. arenarum larvae. Significance levels for Kruskal-Wallis and median tests, ${ }^{*} p=0.09 ; 0 p=0.08$. AZM: azinphosmethyl, CPF: chlorpyrifos, at $6 \mathrm{~h}$ and $24 \mathrm{~h}$ exposures; gene codes are detailed in the text. 
Signaling pathways -

Transcription factors

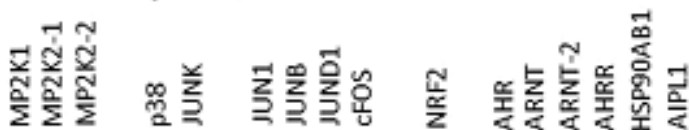

$6 \mathrm{~h}$

AZM

$24 \mathrm{~h}$
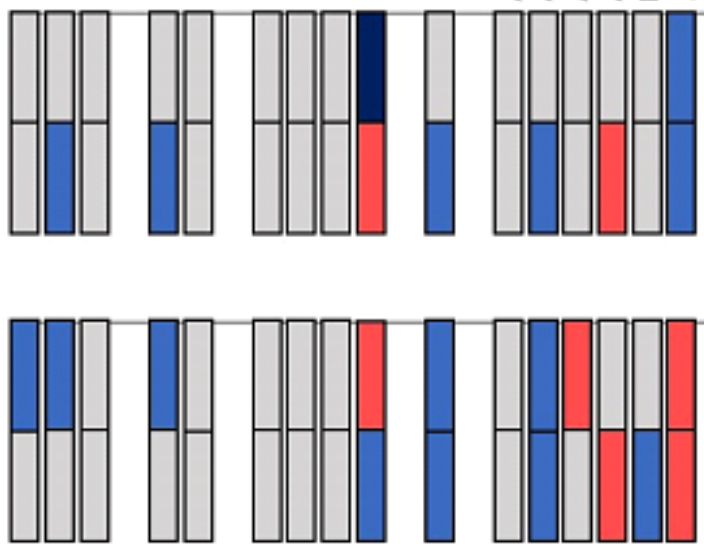

$6 \mathrm{~h}$

CPF

$24 \mathrm{~h}$

Polyamine metabolism Synthesis

Degradation

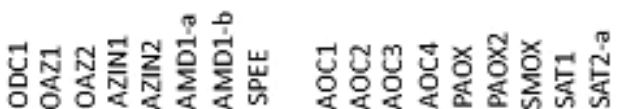

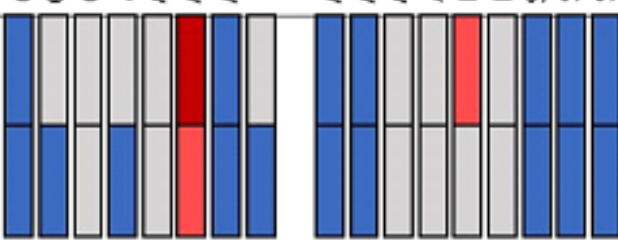

\section{Antioxidant System}

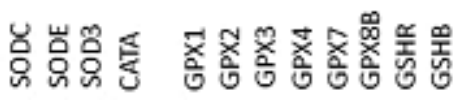

$6 \mathrm{~h}$

AZM

$24 \mathrm{~h}$
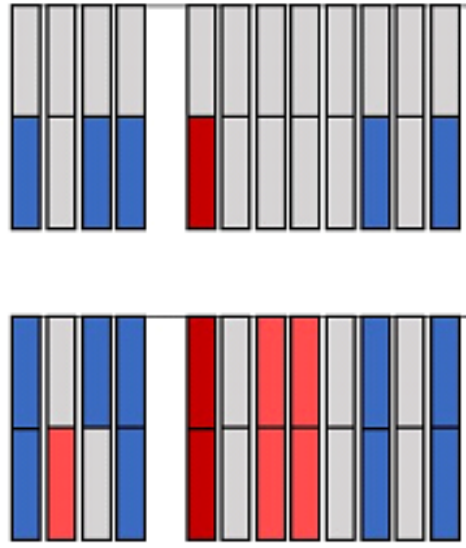

Detoxifying Systems
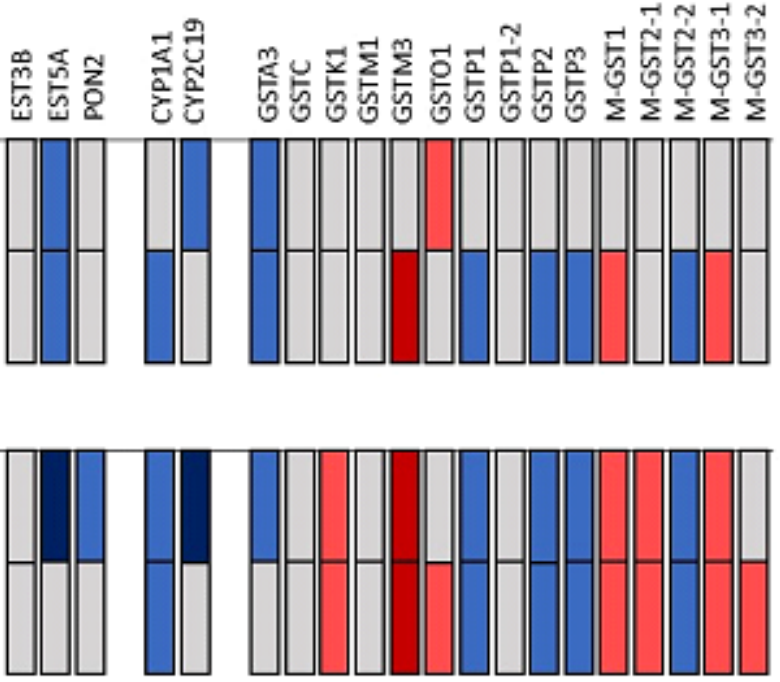

$\log _{2}$ Fold Change:

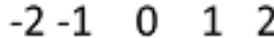

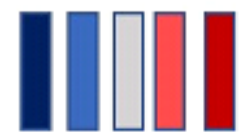

\section{Figure 6}

Heatmap representation of OP effects on selected gene expression in $R$. arenarum larvae.

Data are presented for four groups of selected genes whose products or activities are known or suspected targets of OP pesticides. Larvae were exposed to azinphos-methyl (AZM) and chlorpyrifos (CPF) for 6 and $24 \mathrm{~h}$. Gene codes are detailed in the text. 


\section{Supplementary Files}

This is a list of supplementary files associated with this preprint. Click to download.

- SupplementaryTables.docx

- SUPPLEMENTARYFILEltranscriptchecking.xIsx

- SupplementaryfilellExpressionlevelTMMchecking.xIsx 